\title{
SIMULATION IN THE WOODS: FROM REMOTE SENSING BASED DATA ACQUISITION AND PROCESSING TO VARIOUS SIMULATION APPLICATIONS
}

\author{
Jürgen Rossmann \\ Michael Schluse \\ Ralf Waspe \\ RWTH Aachen University \\ Institute for Man-Machine Interaction \\ Ahornstrasse 55 \\ 52074 Aachen, GERMANY
}

Ralf Moshammer

Technische Universität München

Chair for Forest Growth and Yield

Hans-Carl-von-Carlowitz-Platz 2

85354 Freising, GERMANY

\begin{abstract}
This paper focuses on joint work towards the development of simulation applications in the forest sector. They are based on advanced "semantic" world modeling techniques which use remote sensing data and processing algorithms to derive tree species classification maps, as well as forest stand attributes and single tree databases over large areas. The resulting databases are the basis for a variety of different simulation applications in an integrated system approach. Forest growth simulations aim to predict the appearance of the forest in the next decades. Forest machine simulators allow for an efficient development of forest machines and their control algorithms, as well as for cost-effective driver training. Harvesting cost simulations calculate the harvesting costs long before the lumbermen start to work. Decision support systems enable wood owners and the wood industry to compare different treatment scenarios based on simulations and thus to comprehensively assess ecological and economical chances and consequences.
\end{abstract}

\section{INTRODUCTION}

Nowadays, simulation algorithms are used in nearly all fields of economics, ecology and research. They deliver the basis to assess the behavior of complex systems and are an important part of decision-making processes. But in the forest sector the use of simulation technology is rare so far. Various attempts have been made to simulate forest growth, assess the effects of climate change or set up driving simulators for complex forest machines. But compared to other fields of economy, this is far from a wide and accepted usage of simulation technology as a standard tool in everyday tasks.

From our point of view, the main reason for this is the data acquisition and handling problem. Simulation applications require a detailed model of the environment to be simulated. But it is a major challenge to set up a detailed model for natural environments like the forest, which extends over large areas. It gets even more complicated when data acquisition costs are taken into account. Our concept to overcome this problem is fairly simple:

- Use state-of-the-art remote sensing techniques, which use already existing remote sensing data for a cost-efficient derivation of a simulation friendly forest model. We call this step "Semantic World Modeling," because it goes way beyond topographic mapping and even beyond 3D geometric world models.

- Store the model in a standardized database infrastructure to allow for the easy exchange of algorithms and data 
- Develop different simulation applications to optimize various processes in forestry, concerning costs and quality under economical, as well as ecological aspects

- Provide easy-to-use user interfaces to allow users, which are not computer experts to use these new methods

- Use the same model multiple times for various applications to decrease the data acquisition costs per application once again

For this we are currently using three different types of simulation. At first, standard discrete event simulation (DES) applications calculate the harvesting costs under different boundary conditions long before the lumberman and the forest machines start their work. Quasi-continuous simulation techniques are the basis for driving simulators to train the drivers of highly complex forest machines, to drive them efficiently, while conserving the forest. Moreover, these simulators are the basis for the development of new automation concepts for the further development of forest machines in Virtual Testbed environments. Using the simulation techniques listed so far, methods well known in the field of industrial production become applicable to forestry production. Last but not least, application specific simulation techniques simulate the forest growth under the consideration of different treatment and climate scenarios.

We cover Semantic World Modeling, data storage and simulation algorithms with one integrated system - the so called "Virtual Forest" (see Figure 1). This way, a user can use different simulation algorithms to solve his task, e.g., first determine the trees to be cut in a thinning effort using the forest growth simulator, before using the DES simulator to calculate the harvesting costs or before training this thinning virtually, using the driving simulator.

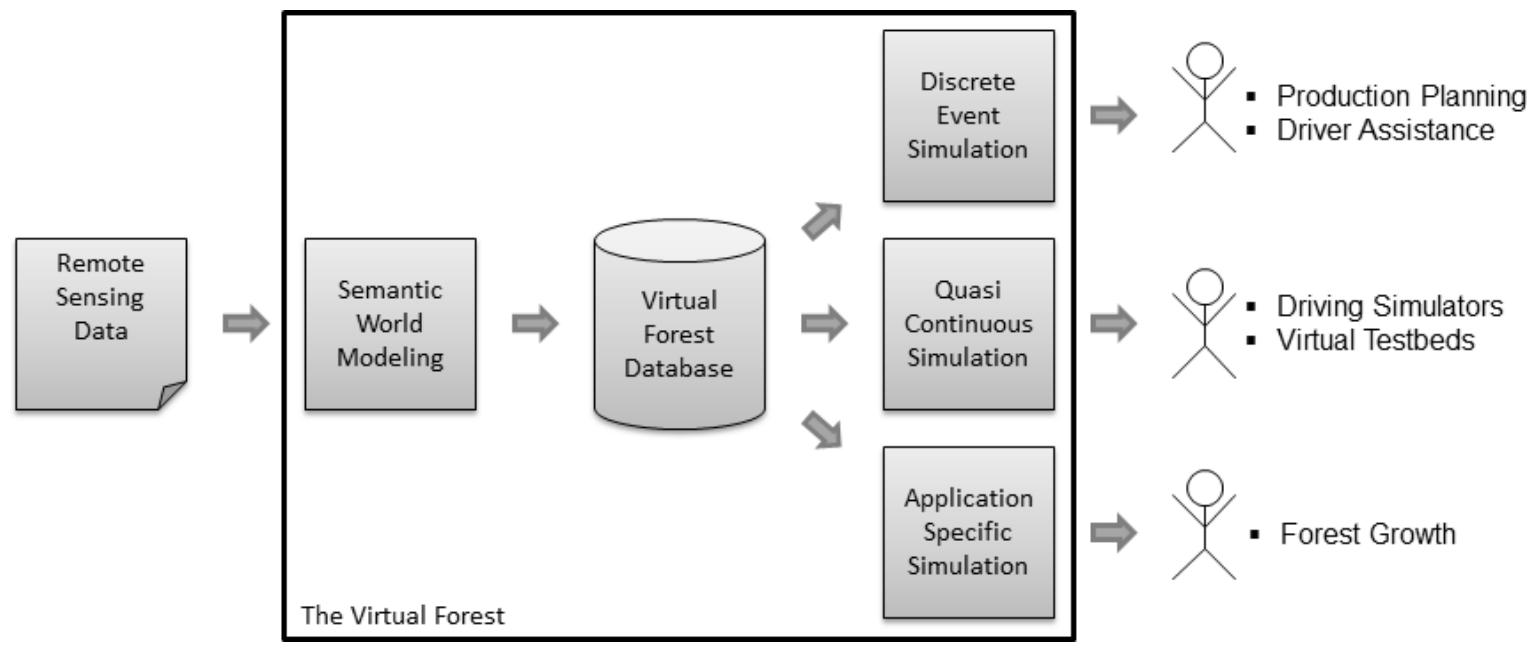

Figure 1: To realize a new integrated system for decision support, assistance, training and development the Virtual Forest integrates Semantic World Modeling with different simulation applications

The Virtual Forest concept benefits nearly all parties being involved in forestry. The forest administration and government can use the Virtual Forest to simulate the consequences of political decisions. Wood owners can test treatment scenarios and calculate harvesting costs as well as wood revenues. Forest machine manufacturers, as well as researchers, can train new drivers and test new automation concepts. Forest machine drivers get useful hints for their work. Forest schools get a comprehensive virtual training environment for education.

The benefits are manifold, but the focus of our current developments is simple: Convince forest owners and provide the necessary methods, to use their forest in an economically and ecologically sensible way, to ensure the raw material basis for the local wood industry, while conserving the forest itself for the future. This way our work delivers major contributions to guarantee the environmental sustainability in 
the forest, while enhancing the competitiveness of the forest industry at the same time. The latter is even important in highly industrialized countries like the state of North-Rhine Westphalia in Germany. Here, $27 \%$ of the country's territory is covered by wood land, $7.2 \%$ of the gross domestic product is generated by forest and wood industry and 3\% of all employees are working in the forest sector.

The rest of this paper is organized as follows. Section 2 gives a short overview of related work in the field of forest management and simulation. Section 3 introduces the 4D-GIS, the software framework and the corresponding data infrastructure which is the basis for nearly all developments introduced later. The Semantic World Modeling techniques, which are used to generate a virtual forest model, are within the focus of section 4. Section 5 illustrates the three major simulation applications of the Virtual Forest and Section 6 gives a conclusion.

\section{RELATED WORK}

Different aspects of the Virtual Forest Project are already within the focus of different research activities. These range from the development of methods for the classification of tree species (Leckie et al. 2005; Pinard and Bannari 2003; van Aardt 2000; Törmä et al. 2000; Persson et al. 2004; Kamagata et al. 2005; etc.) to forest information systems (ZEUS 2011; Felbermeier and R. Mosandl 2003; Bruchner 2003; Saxon-Bohemian Forest 2011; USDA 2011; etc.), as well as to collaborative projects that focus on different aspects along the value chain in the forest (MatchWood 2011, etc.). Also the use of simulation techniques is not new. Besides different projects in the field of simulation of climate scenarios, driving simulators are sold by all major forest machine manufacturers (e.g., Oryx 2011). But still missing is an integrated approach as it is suggested by the Virtual Forest concept, which links the different results to each other and uses the resulting potential for synergy.

\section{THE 4D-GIS}

We are integrating the different simulation algorithms in a 3D geo-information system (3D-GIS) resulting in a new kind of 4D-GIS, which not only allows the user to look back into the data history, but also simulate what might happen under different conditions in the future.

\subsection{Basic concept}

Figure 2 outlines the basic structure of the 4D-GIS from a simulation systems point of view. First of all remote sensing data, as well as other already existing spatial data, is fed into a spatial database. After that, Semantic World Modeling techniques (see section 4) are used to derive forest stands, as well as single trees and their attributes. The results are written back to the database, building the basis for the three simulation applications (see section 5).

To realize a highly integrated GIS-based simulation system, care has to be taken in developing a powerful, yet flexible data infrastructure. It must be fast enough to allow for real-time simulation applications, it must support modern object-oriented data modeling techniques to allow for a semantic world modeling and it has to provide enough storage capacity for a vast amount of geographical and other data. To resolve these partially conflicting requirements we developed a two-tiered architecture that combines an object-oriented internal real-time simulation database with external object-oriented active geo databases using an intelligent database interface, which synchronizes their schema and data (see Figure 2).

In this architecture, the simulation database can be seen as an abstraction layer of the external database, hiding away the specific DBMS (database management system) from the simulation system and its users. Based on the interface's read-write access, the external database also serves as a persistence layer for the simulation system, providing features like access rights management and versioning on attribute level. Attaching more than one simulation client, an active external database can even be used as a central data storage and communication hub for collaborative data access and distributed simulation applications, where changes by one client are actively pushed to all other participating clients 


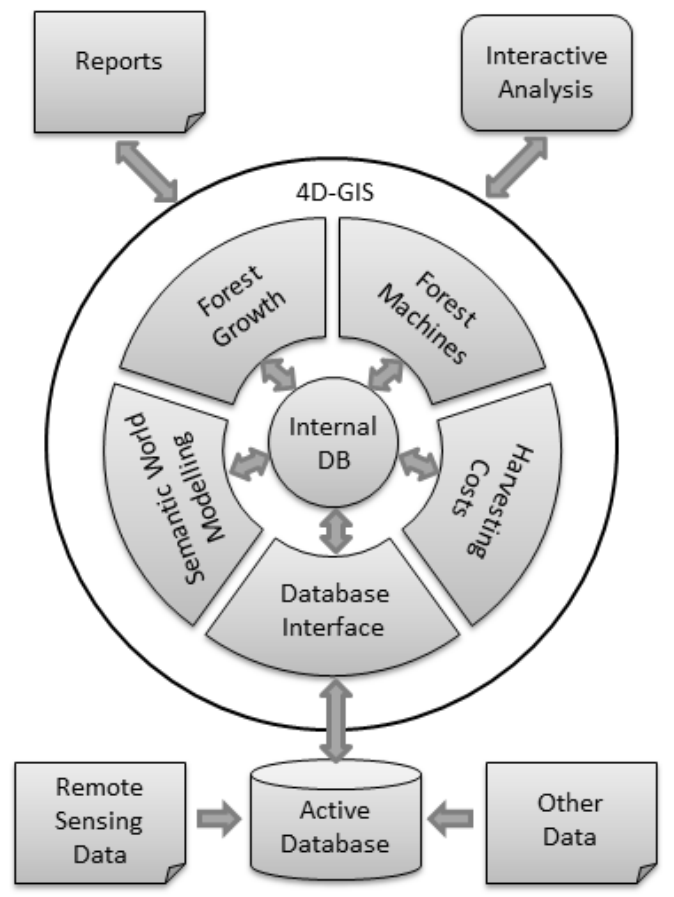

Figure 2: Overall structure of the Virtual Forest 4D-GIS from a simulation point of view

\subsection{Internal Simulation Database}

The internal database is an event driven and object-oriented graph database, which describes components (nodes), as well as their behavior and provides methods for parallel and distributed computing and visualization. Nodes not only provide data encapsulation but also mechanisms for interaction with the simulation environment implementing their behavior - this is what distinguishes this database from standard scene graphs. For example nodes that are derived from a "Simulation Task" provide functions that get called periodically by the simulation core.

All components of the database are derived from an "Instance" class. Simulation data as well as the topology of the database is stored in so called properties. Using an "active" database means that whenever a property is changed a signal is sent to all registered listeners. Different aspects of the simulation system only need selected views of the simulation database ignoring all nodes not relevant to the task. This is achieved by using indexed element lists provided by the database container, thus eliminating the need of simulation components to traverse the complete database.

Reflection is provided by so called meta-instances describing classes of instances (name, inheritance, etc.) and meta-properties describing their properties (name, type, multiplicity, etc.). This enables the simulation system to query meta-instances and meta-properties by name. Dynamic schema generation allows for the creation of new meta-instances and meta-properties at run-time. This is used to enable the synchronization process of the database interface.

\subsection{External Database}

As an external data management system we are currently using the GML (Geography Markup Language) database management system SGJ (SGJ 2011). This object-oriented geo DBMS offers instantiation of XML Schema Definition (XSD). This allows for the definition of arbitrary classes, inheritance hierarchies, relations and attributes. SGJ can be controlled using its proprietary Java API with a kernel-based architecture, which allows full access to schema properties (classes, attributes and relations) and object data. 
SGJ complies with several OGC (Open Geospatial Consortium) standards. Data can be modeled conforming to GML, geometries are represented as Simple Features, Styled Layer Descriptors (SLD) can be used to build maps for its Web Map Service (WMS) and data can be read and written using its transactional Web Feature Service (WFS-T). Its standard compliance guarantees access to the data from different applications on different platforms. Thus, different tools on different platforms can be used to build up the environment for a simulation and clients other than the simulation system can access the data.

\subsection{Database Interface}

As mentioned above we use an intelligent database interface that makes data available to the simulation system by synchronizing schema and data. By replicating objects from the external database to the simulation database and keeping them "in sync" additional benefits beyond the object data synchronization are achieved. The data schema of the external database is also replicated and thereby instantiated in the internal database making both "speak the same language" and providing a common data schema for the whole system. This way the system shows great flexibility towards changes in the data, i.e., to objects or even to the schema itself.

This approach has several advantages over the direct usage of database objects within the simulation system. By using the (replicated) objects in the internal database, details of the actually used database are hidden from all internal components of the simulation system (particles, physics, sensor data processing, rendering, etc.) allowing for transparent data access and real-time visualization and simulation. The internal simulation database works as an "intelligent" data cache to speed up repeating access patterns, which would otherwise lead to repetitive queries to the external database. Using mechanisms for piecewise data loading and unloading from the external database, e.g., based on the users position in a virtual simulation environment, huge datasets can be accessed (e.g., data from a vast tree database). Additionally, using an external database provides the simulation system with persistence, as changes made to replicated objects can be resynchronized back into the database. Other clients or tools can still directly access the database without invalidating the dynamic two-level synchronization as a whole.

\section{SEMANTIC WORLD MODELING}

When setting up the world model of simulation applications it is not enough to derive raster information from remote sensing data, which is common in remote sensing technology today. Simulation applications need "objects" which have a meaning, whose properties are described by a set of attributes and who represent real world entities in a simulation friendly way. We call this process of deriving such objects from remote sensing data "semantic world modeling." Figure 3 illustrates the different aspects of semantic world modeling within the forestry context. At first, a tree species map and a map of potential tress are calculated. Using this, forest stands are delineated and stand attributes are calculated. The modeling process ends with a single tree segmentation step. A tree sample inventory delivers the necessary ground truth information for this.

\subsection{Tree species classification}

Tree species data is a very important source of information in the forest. It is needed for inventories, estimation of age as well as other forestry parameters and simulations of future developments of a forest area. Airborne color (RGB) and color-infrared (CIR) images in combination with airborne LIDAR data and multispectral satellite data have proven to be a good and affordable data basis for this.

As described in (Krahwinkler and Rossmann 2011), a support vector machine based approach is used to classify multiple species. Support vector machines separate two classes by searching for a hyperplane with two accompanying parallel hyperplanes, such that the two classes are separated by the margin between the accompanying hyperplanes. Seven classes are used in the classification scheme, namely Oak, Beech, other broadleaved trees, Pine, Larch, Spruce and Douglas Fir. 


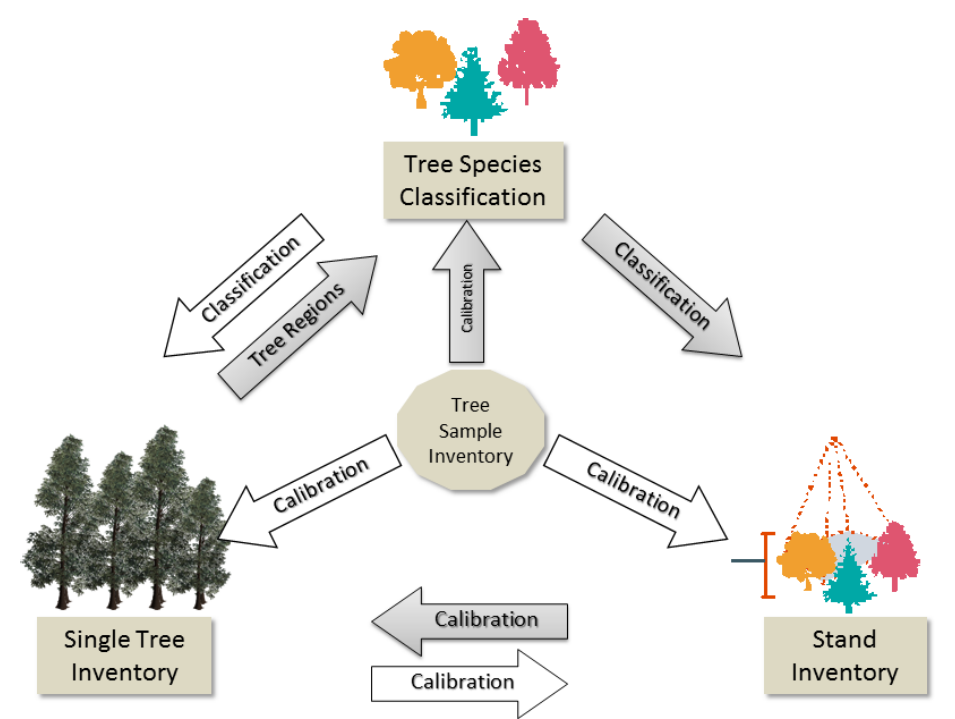

Figure 3: Aspects of Semantic World Modeling in the forest

For the decision tree induction, at each node all possible separations of the classes into two sets of almost the same size are calculated. For each of these combinations, the Fisher distance is calculated and the pair of class groups with the highest value for the distance measure is chosen. The support vector machine is trained with the two species groups as the two input classes. Figure 4 shows a deduced support vector machine based decision tree including 5-fold cross validation results during training at each inner tree node.

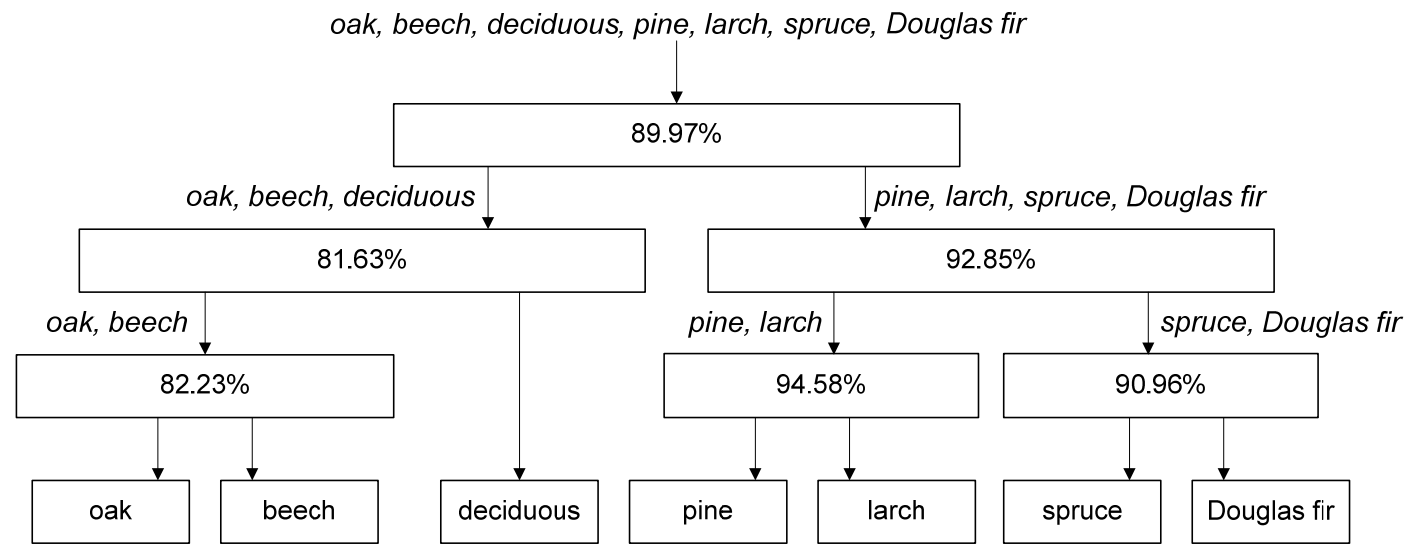

Figure 4: Support vector machine based decision tree and 5-fold cross validation results.

During classification, a measure, representing the distance from the hyperplane is calculated at each node. To estimate not only the species but also the reliability of the classification not only the sign, but also the absolute value must be considered. Smaller values are calculated for input vectors that are close to the decision boundary and therefore the classification is more uncertain than for classifications with large absolute values. Figure 5 (left) illustrates the results of the classification process.

\subsection{Stand Inventory}

In North Rhine-Westphalia (NRW) and other German states the forest is separated into forestry units. Generalization algorithms have been developed to derive the geometry of such forestry units. They calcu- 
late similarity measures to merge similar tree regions into a forest stand. Figure 5 (right) illustrates the results of a generalization of a land parcel (Rossmann et al. 2009a).

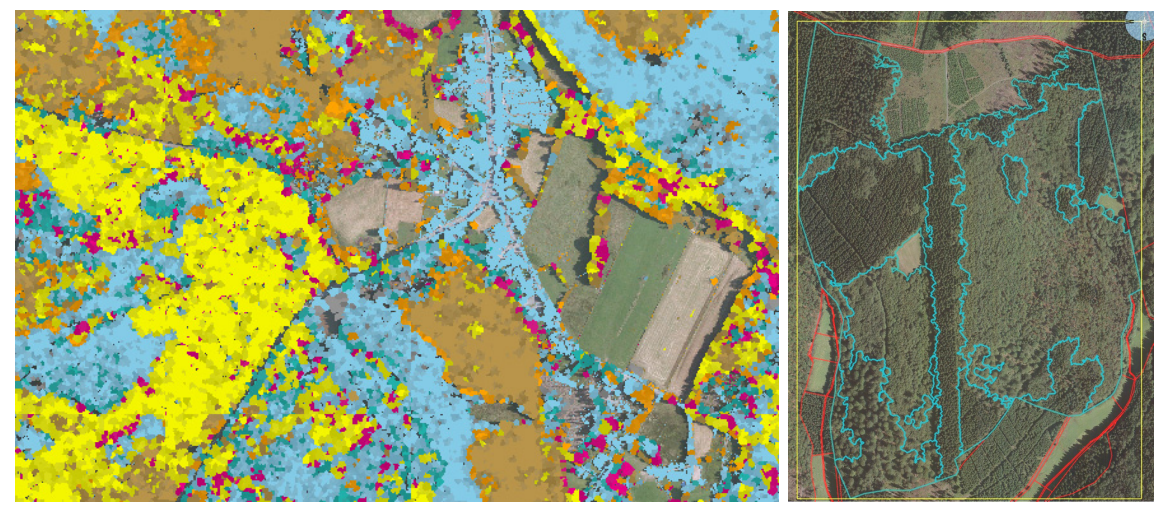

Figure 5: Example of the tree species classification (left) and of the stand generalization (right)

For each tree species within a forestry unit age, dominant height and a so called yield class are used to calculate the timber volume as a dependent value. The species mixture can be calculated out of the tree species (see section 4.1), while the stock density is related to the percentage of sheltered area in the unit.

The second important attribute to characterize the trees of one species in a forestry unit is either the age of the trees or the yield class. In all state owned and some private owned units the age and yield class is known and can be obtained from the previous forest inventory. In other units the yield class can be estimated by using information about hydrology and trophic level obtained by a site classification (Asche and Schulz 2006), which is available for most units in North-Rhine-Westphalia. Comparisons on units of about 1200 ha have shown that the amount of timber volume that was calculated with this approach differed only by two percent from the volume that was estimated by a surveyor for the same region.

\subsection{Single Tree Inventory}

The stand inventory is the calibration basis for automated single tree delineation algorithms, which fill a database of individual trees using remote sensing data. The Volumetric Algorithm (Buecken and Rossmann 2009) illustrated in Figure 6 provides an effective solution to delineate individual trees in a forest that is described by an nDSM (normalized digital surface model, shown far left). To get volumetric information we, figuratively spoken, fill the nDSM with water (middle left). Then, in turn, the point with the highest water-level is "opened", the flow of the water is simulated and the amount of water that drains out of the opening is measured (middle right). The interesting feature is that the resulting volume emphasizes peaks that are dominant in the surrounding. For each volume that is higher than a threshold a tree is generated. With an optimized implementation this algorithm reaches linear complexity.

Each tree is annotated with its height, its species (from the tree species classification) and the average crown diameter that is visible in the remote sensing dataset (Nagel and Schmidt 2001).

\section{SIMULATION APPLICATIONS}

In the Virtual Forest project, the single tree database is now the basis for three different simulation applications, forest growth simulations, forest machine simulations and Virtual Testbeds, as well as harvesting cost simulations.

\subsection{Forest Growth Simulations}

During the last few decades the perception of sustainability in forest management has dramatically changed from a one-dimensional, timber-production oriented view towards a multi-criterial view. Finding 
an optimal management concept for forest stands and enterprises has become a high-dimensional problem. Therefore forest managers' need for information and decision support has multiplied. This information demand on the one hand and the available data on the other are the basis for a new generation of forest growth models, which are very flexible with regard to silvicultural concepts, species mixtures and site conditions and which offer a broad multi-criterial spectrum of output variables. It is common that forest growth simulators can provide that kind of essential information for the management of forest enterprises (Moshammer, Rötzer, and Pretzsch 2009).
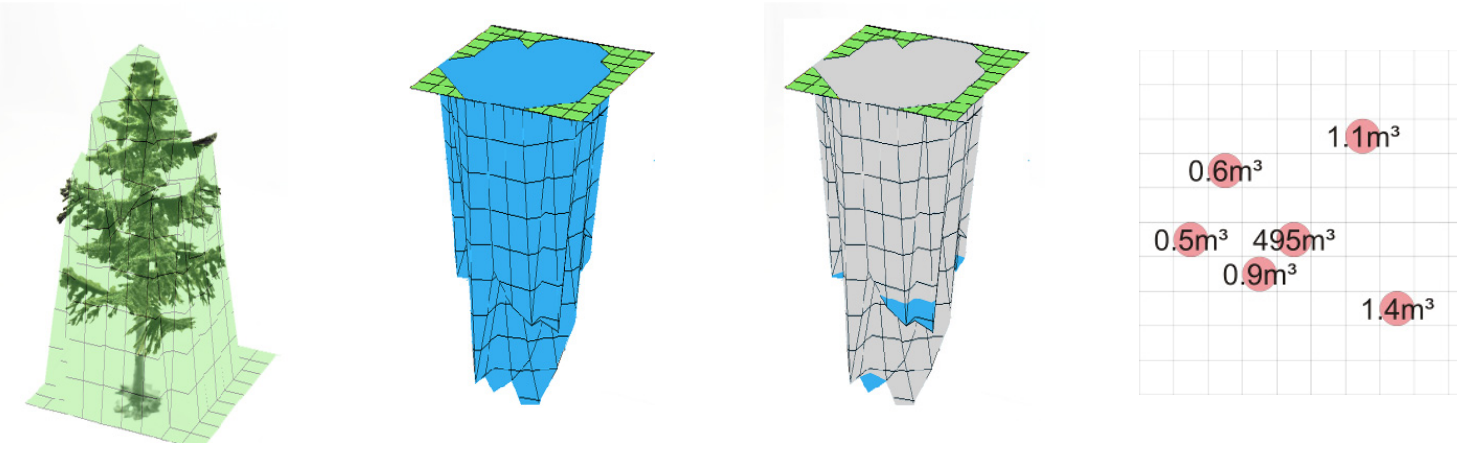

Figure 6: The Volumetric Algorithm: A tree, its flipped nDSM filled with water, the first cycle of the algorithm and the calculated volumes.

The forest growth simulator SILVA, which is used for forest growth simulation in the Virtual Forest system (Figure 7) uses a distance-dependent and environmentally sensitive individual tree model (Pretzsch, Biber, and Dursky 2002). In SILVA, each single tree is defined by a compound of several functions as shown in Figure 8. The smallest simulation time step with SILVA is a period of five years, which is the time interval corresponding with the time intervals provided by yield tables. The implemented algorithms were parameterized from long-term experimental plots in Germany (Kahn 1994; Pretzsch, Biber, and Dursky 2002). The individual-tree approach allows the user to create rules for a virtual thinning, which also takes place every five years.
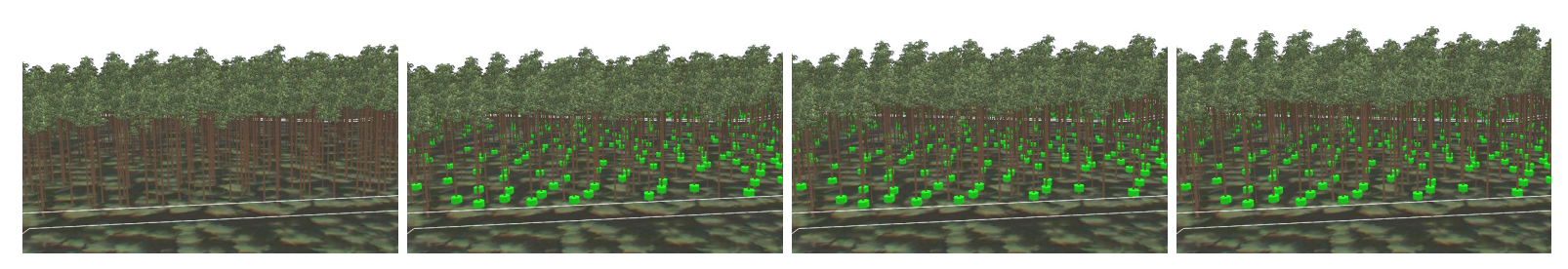

Figure 7: Simulation results of the forest growth simulator, the marked trees are important for the future growths of the stand

For the simulation of realistic silvicultural activities the conventional thinning concepts are embedded in the program along with guidelines for thinning intensity, harvesting intervals and upper limits for the harvested wood volume, so that a large number of management options can be simulated. The simulator automatically decides which concept to use for which stand, dependent on its characteristics, e.g., site conditions, species, mixture, development stage. As default, three different scenarios of thinning intensity are calculated automatically in order to make the corridor of action for the forest management evident.

Interacting with the 4D-GIS environment, SILVA can be used in two different ways. On the one hand the basis for forest simulations can be delivered out of the 4D-GIS database by processed remote sensing 
data. On the other hand SILVA can be used to generate virtual single tree based stands out of stand descriptions of the forest management, to fill in the 4D-GIS database, in places where no or not sufficient remote sensing data is available.

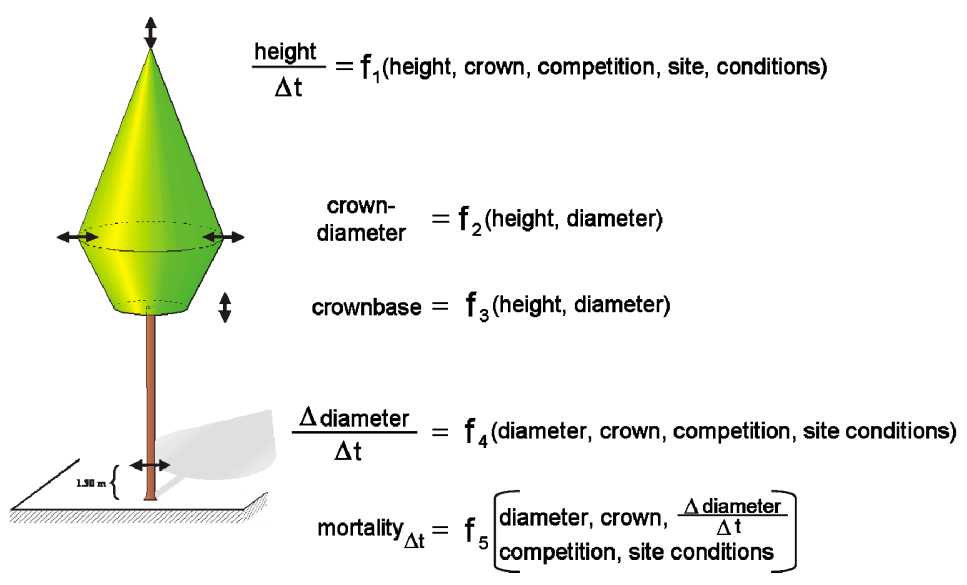

Figure 8: Functions for regulation of the individual tree growth

\subsection{Forest Machine Simulation and Virtual Testbeds}

Simulation combined with original board computers and machine controls has become an essential part in education and training of forest machine operators, who can get used to the machine controls and get an intuition for the dynamic behavior of the crane and the whole machine. Early training simulators were based on purely kinematic simulation techniques concerning the simulation of motion (e.g., Freund, Rossmann, and Kraemer 2002). For the machines themselves, this would be acceptable as their analogy to industrial robots allow the use of well-known modeling techniques from this area. However, once these machines interact with the natural environment of the wood, these modeling techniques fail - for example in predicting the varying behaviors of cut trees or the many problems that may appear when a forwarder loads logs into its loading area.

To overcome these weaknesses, modern forest machine simulators are based on physics based simulation systems (e.g., Jung \& Rossmann 2007). Figure 9 gives an impression of our current 3D-forest machine simulation. This results in a more realistic dynamic behavior and even reduces the efforts for creating new simulations. While previous wood environments were mainly results of artistic freedom, the Virtual Forest database supplies the forest machine simulators with training environments, which are as close to reality as possible. Trainees can learn in an environment which looks like their future workplace, whereas machine operators can plan and simulate actual wood harvests. The practicability of potential skid roads can be evaluated in advance, as the Virtual Forest supplies the simulated environment with information about soil conditions and slope. Herein the latter is not just presented as abstract, numerical information. The operator can even evaluate the quality of a skid road with respect to the reachability of single trees. It automatically offers a nearly infinite number of simulation environments, so that no additional modeling effort has to be taken. From a developers point of view this approach dramatically reduces the costs for modeling virtual wood environments for the simulators.

In addition to this, these simulation algorithms are the basis of a comprehensive engineering tool for the further development of automation concepts of forest machines, the so called Virtual Testbed (Rossmann 2009). For this, various sensors and actuators, as well as their sensor data processing and control algorithms can be added to the simulation model, e.g., to test new localization concepts using laser scanners (Rossmann et al. 2009b). 

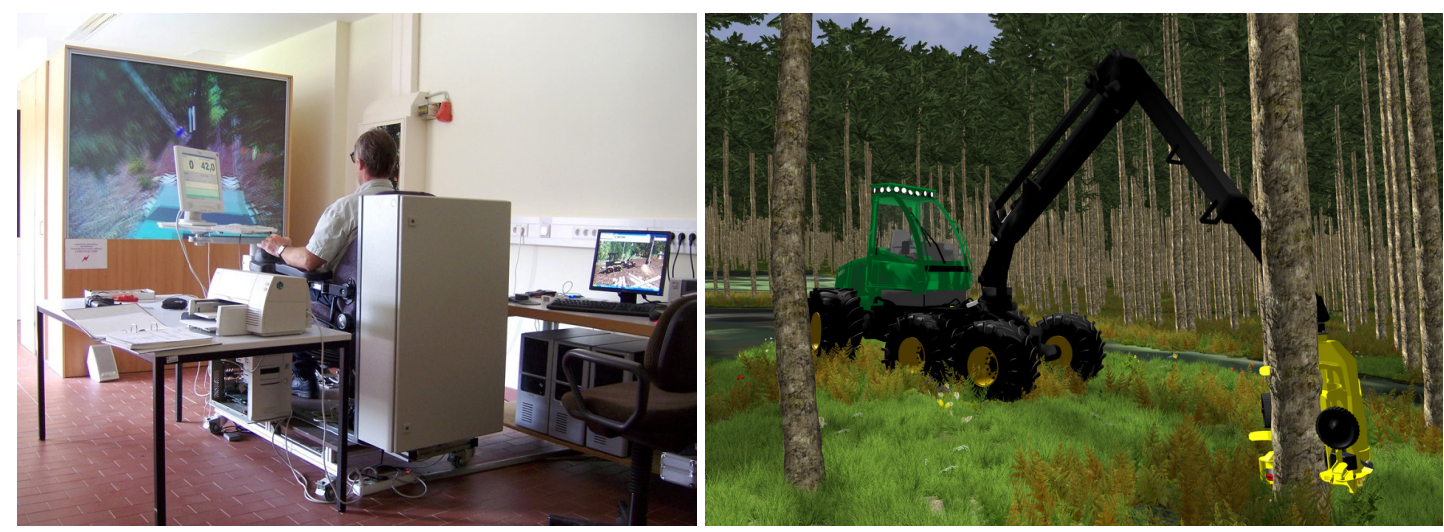

Figure 9: Photo of a forest machine simulator in the field taken in a forestry school in Germany (left), screenshot of a Virtual Testbed scenario (right)

\subsection{Harvesting Cost Simulations}

The harvesting cost simulation application delivers important economic data for a goal oriented planning of efficient harvesting measures. It uses methods based on the work of Hemm, Ziesak and Warkotsch (2006) and Hemm (2006) and is implemented as a discrete event simulation (DES), which allows to quickly calculate harvesting scenarios (see also Rossmann and Alves 2009). The simulation starts with trees marked for felling by the forest growth simulation and incorporates the available roads and resources.

The simulation results can be viewed either in an online visualization or as a table summary as shown in Figure 10. One major aspect of the simulation is the routing of the vehicles used, which is based on a graph which is created from geo data. The routing algorithm takes into account the reachability of the trees, which are added from the database and are associated with the nearest edge of the graph. The harvesting costs are deduced by calculating the duration of the harvest and applying time/cost tables.

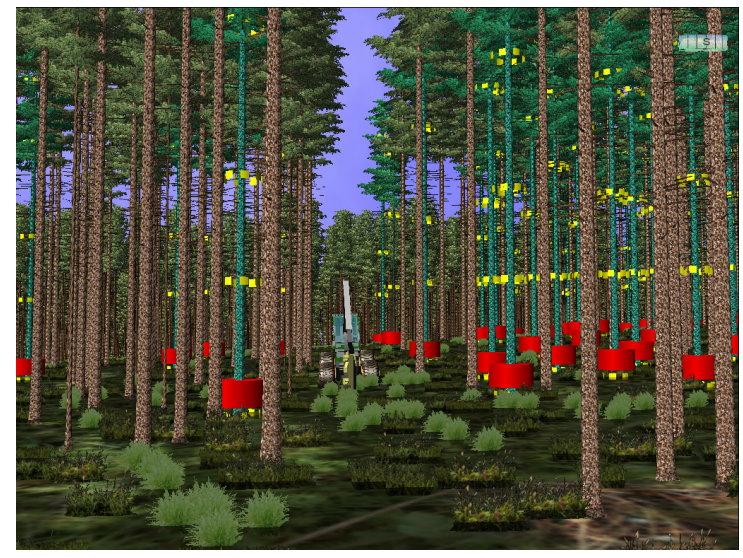

\begin{tabular}{l|l} 
Wood revenue & $+3935 €$ \\
\hline Harvesting costs harvester & $-975 €$ \\
\hline Harvesting costs forwarder & $-863 €$ \\
\hline Total revenue & $=2097 €$
\end{tabular}

Figure 10: Results of the harvesting costs simulation (trees to fell, segments to cut, costs and revenues)

Besides its function as a planning tool, the harvesting cost simulation with the routing information can also be used as the basis for a single tree navigation system, which assists the driver in finding the most efficient way to the nearest tree to be felled. 


\section{CONCLUSION AND OUTLOOK}

This paper introduces the combination of modern remote sensing with state-of-the-art simulation technology resulting in an integrated forest management system, the "Virtual Forest". This approach paves the way for the wide usage of simulation technology in everyday tasks in the forest sector. The overall goal is very ambitious, but first results have been really promising. The remote sensing algorithms are well able to derive a close-to-reality model of the physical forest. This capability has already been verified in large test areas of approx. $1,000 \mathrm{~km}^{2}$. The forest growth simulator in turn calculates the future development of the modeled forests and provides a sustainable basis, for complex decisions concerning forest treatment.

The developed methods do not only focus on the "biological production", also the "technical production", i.e., the use of harvesting machinery in the woods is of great interest. Currently, an intensive evaluation of the harvesting cost simulator's results and its use for harvester driver assistance is being conducted. In addition, plans to integrate the results of simulation applications mentioned above in easy-to-use (desktop and online) decision-support-systems for forest owners, forest administration as well as forest and wood industry are being pursued.

\section{ACKNOWLEDGMENTS}

This paper gained from contributions of Arno Bücken, team leader at the Institute for Man Machine Interaction (MMI), and Thomas Jung, Petra Krahwinkler and Martin Hoppen, research assistants at MMI.

The Virtual Forest project is co-financed by the European Union and the federal state of North RhineWestphalia, European Regional Development Fund (ERDF). Europe - Investing in our future.

\section{REFERENCES}

Asche, N., and R. Schulz. 2006. "Forstliche Standortklassifizierung mit digitalen Werkzeugen in Nordrhein-Westfalen." Landesbetrieb Wald und Holz NRW. Accessed February 25. http://www.wald-und-

holz.nrw.de/30Wald_und_Beratung/Forstliche_Standorterkundung/staka_klassifikation.pdf.

Buecken, A., and J. Rossmann 2009. "Detecting Trees in Lidar Data - A Foundation for a Forest Inventory Based on Remote Sensing Data." In: Proceedings of the Remote Sensing and Photogrammetry Society Annual Conference "New Dimensions in Earth Observation"(RSPSoc 2009), 611 - 615. Leicester, UK, 8-11th September.

Bruchner, A.-K. 2003. "Industrielle Simulationssoftware als Entscheidungsunterstützungsinstrument in der Produktionslogistik der Holzerntekette.” PhD-Thesis, TU Munich, Germany.

Felbermeier, B., and R. Mosandl. 2003. "Multiobjective Decision Making in Silviculture." In Proceedings of IUFRO Decision Support for Multiple Purpose Forestry, April 23-25, 2003, Vienna, Austria.

Freund, E., J. Rossmann, and M. Kraemer. 2002. "Robots in the Woods: The Challenges to Simulate a Wood Harvester." VDI-Berichte, 633-639.

Hemm, M. 2006 "Simulating Harvesting Operations by Using the Software Automod to Model a Certain Test Stand of the Forestry Office Paderborn." Dissertation, Wissenschaftszentrum Weihenstephan, TU Munich.

Hemm, M., M. Ziesak, and W. Warkotsch. 2006. "Simulating Harvesting Procedures to Evaluate Different Working Systems Based on Discrete Single Tree Events." In: Proceedings of the International Precision Forestry Symposium, edited by P. A. Ackerman, D. W. Längin, and M. C. Antonides. Stellenbosch University, South Africa, Stellenbosch.

Jung, T. J., and J. Rossmann. 2007. "Realisierung von Simuatoren fuer Forstmaschinen fuer den Einsatz in der Maschinenfuehrerausbildung mit einem universellen 3D-Simulationssystem." In Virtual Reality und Augmented Reality zum Planen, Testen und Betreiben technischer Systeme, edited by P. D.-I. Schenk, 115-121. Fraunhofer IFF.

Kahn, M. 1994. "Modellierung der Höhenentwicklung ausgewählter Baumarten in Abhängigkeit vom Standort." Forstliche Forschungsberichte Nr. 141. 
Kamagata, N., Y. Akamatsu, M. Mori, Y. Qing Li, Y. Hoshino, and K. Hara. 2005. "Comparison of Pixel-Based and Object-Based Classifications of High Resolution Satellite Data in Urban Fringe Areas." In Proceedings of the 26th Asian Conference on Remote Sensing, Hanoi, Vietnam.

Krahwinkler, P., and J. Rossman. 2011. "Support Vector Machines Based Decision Tree for Very High Resolution Multispectral Forest Mapping." IEEE International Geoscience and Remote Sensing Symposium, Vancouver (to be published).

Leckie, D. G., S. Tinis, T. Nelson, C. N. Burnett, F. A. Gougeon, E. Cloney and D. Paradine. 2005. "Issues in Species Classification of Trees in Old Growth Conifer Stands." Canadian Journal of Remote Sensing 31:175-190.

MatchWood. 2011. "MatchWood - Vom Baum zum Produkt." Accessed February 25. http://www.matchwood.uni-freiburg.de/.

Moshammer, R., T. Rötzer and H. Pretzsch 2009. "Analyse der Waldentwicklung unter veränderten Umweltbedingungen - Neue Informationen für die Forstplanung durch Kopplung von Modellen am Beispiel des Forstbetriebes Zittau." AFSV; Waldökologie, Landschaftsforschung und Naturschutz (Forest Ecology, Landscape Research and Nature Conservation) 8:63-70.

Nagel, J., and M. Schmidt 2006. "The Silvicultural Decision Support System BWINPro.” In: Sustainable Forest Management, Growth Models For Europe, edited by H. Hasenauer, 59-63. Springer.

Oryx. 2011. "Oryx Simulations." Accessed June 3. http://www.oryx.se/products/valmet-harvester/.

Pretzsch, H., P. Biber, and J. Dursky. 2002. "The Single Tree-Based Stand Simulator SILVA: Construction, Application and Evaluation." For. Ecol. Manag. 162:3-21.

Pinard, V., and A. Bannari. 2003. "Spectroradiometric Analysis in a Hyperspectral Use Perspective to Discriminate Between Forest Species." In Proceedings of Geoscience and Remote Sensing Symposium 2003 (IGARSS '03), 7:4301-4303. IEEE International.

Persson, Å., J. Holmgren, U. Söderman, and H. Olsson. 2004. "Tree Species Classification of Individual Trees in Sweden by Combining High Resolution Laser Data with High Resolution Near-Infrared Digital Images." In Proceedings of the ISPRS Working Group VIII/2: Laser-Scanners for Forest and Landscape Assessment, 1:3-6. Freiburg, Germany.

Rossmann, J. 2009. "From Space to the Forest and to Construction Sites: Virtual Testbeds Pave the Way for New Technologies." In: Proceedings of the the 2nd Sino-German Workshop "Virtual Reality \& Augmented Reality in Industry", edited by D. Ma, J. Gausemeier, X. Fan, and M. Grafe, 39-54. Berlin: Springer.

Rossmann, J., and G. Alves. 2009. "A Detailed Timber Harvest Simulator Coupled with 3-D Visualization." In: World Academy of Science, Engineering and Technology (WASET Journal), 57:243-248.

Rossmann, J., M. Schluse, A. Bücken, P. Krahwinkler, and M. Hoppen. 2009a. "Cost-Efficient SemiAutomatic Forest Inventory Integrating Large Scale Remote Sensing Technologies with GoalOriented Manual Quality Assurance Processes." In: IUFRO Division 4 Conference "Extending Forest Inventory and Monitoring over Space and Time, May 19-22, 2009, Quebec City, Canada.

Rossmann, J., M. Schluse, C. Schlette, A. Bücken, P. Krahwinkler, and M. Emde. 2009b. "Realization of a Highly Accurate Mobile Robot System for Multi Purpose Precision Forestry Applications." In: The 14th International Conference on Advanced Robotics (ICAR 2009), 133-138. June 22-26, Munich.

Saxon-Bohemian Forest. 2011. "Information Portal about Forest and Forestry of the Neighbouring Border Regions of Saxony, Czechia and Poland.” Accessed February 25. http://www.silvaportal.info/.

SGJ. 2011. CPA Systems GmbH. Accessed February 27. http://www.cpa-systems.de.

Törmä, M. 2002. "The Extraction of Tree Species Information of Forest Stands Using Satellite Images." In Proceedings of Geoscience and Remote Sensing Symposium 2000 (IGARSS 2000), 438-440. IEEE International.

USDA. 2011. "Forest Inventory Analysis." U.S. Department of Agriculture, Forest Service. Accessed February 25. http://nrs.fs.fed.us/fia/.

van Aardt, J. A. 2000. "Spectral Separability among Six Southern Tree Species." M. S. Thesis, Virginia Polytechnic Institute and State University, Blacksburg, VA, USA. 
ZEUS. 2011. ZEUS - Zukunftsorientiertes, forstliches Entscheidungsunterstützungssystem. Accessed February 25. http://www.wwk.forst.wzw.tum.de/research/projects/zeus/.

\section{AUTHOR BIOGRAPHIES}

JUERGEN ROSSMANN studied electrical engineering at the Universities of Dortmund and Bochum, Germany. After his studies he worked as a researcher and team leader at the Institute of Robotics Research (IRF) in Dortmund. He received his doctorate in 1993 and was named junior professor for robotics and computer graphics at the University of Southern California in 1998. He habilitated in 2002 at the University of Dortmund and was managing director of EFR-Systems GmbH in Dortmund from 2005 to 2006. Since 2006 he is director of the Institute of Man-Machine Interaction and full professor at the RWTH Aachen University in Aachen, Germany. His research interests are projective virtual reality, multi-agent control and supervision, multi-sensor integration, system simulation and optimization techniques, computer vision, real-time visualization and man-machine interaction. His email address is rossmann@mmi.rwth-aachen.de.

MICHAEL SCHLUSE studied electrical engineering at the University of Dortmund, Germany. Between March 1996 and February 2005 he was researcher and team leader "System Technology" at the Institute of Robotics Research (IRF) in Dortmund. In May 2002, he received his doctorate at the University of Dortmund. Between March 2005 and March 2006 he was department head at the EFR-Systems GmbH and responsible for the development of modern 3D simulation technologies and versatile Virtual Reality systems. Since April 2006 he is senior engineer at the Institute of Man-Machine Interaction at the RWTH Aachen University. His email address is schluse@mmi.rwth-aachen.de.

RALF WASPE studied theoretical physics at Queen Mary College, University of London, UK. Between 2001 and 2005 he was research assistant at the Institute of Robotics Research (IRF) in Dortmund, and between 2005 and 2006 software developer at EFR-Systems GmbH in Dortmund. Since 2006 he is team leader at the Institute of Man-Machine Interaction at the RWTH Aachen University. His email address is waspe@mmi.rwth-aachen.de.

RALF MOSHAMMER is graduated forest engineer and research scientist at the Chair of Forest Growth and Yield Science at the Technische Universität München in Munich, Germany. His field of interest is forest growth simulation pertaining to forest inventory and forest management on enterprise and landscape level. With his experience in modeling, data analysis and forest optimization, as well as practical field work, he is acting as a link between forest science and forest practitioners. His email address is ralf.moshammer@1rz.tu-muenchen.de. 